RESEARCH ARTICLE

\title{
Potentially zoonotic gastrointestinal parasites of dogs in Lunugala Tea estate community in Central Sri Lanka
}

\author{
K.O. Bandaranayaka ${ }^{1,2}$, R.P.V.J. Rajapakse ${ }^{3}$ and R.S. Rajakaruna ${ }^{1,2, *}$ \\ ${ }^{1}$ Department of Zoology, Faculty of Science, University of Peradeniya, Peradeniya, Sri Lanka \\ ${ }^{2}$ Postgraduate Institute of Science, University of Peradeniya, Peradeniya, Sri Lanka \\ ${ }^{3}$ Department of Veterinary Pathobiology, Faculty of Veterinary Medicine and Animal Sciences, University of \\ Peradeniya, Peradeniya, Sri Lanka
}

Received: 23/08/2018; Accepted: 16/01/2019

\begin{abstract}
Coprological examination of gastrointestinal (GI) parasites and their life stages in humans and dogs and in soil was carried out in a low income tea estate community in the Central Province. This community has limited access to public health facilities and veterinary services and lives in close contact with free roaming dogs. Parasites in faeces were isolated and identified morphologically and morphometrically using microscopical methods, followed by molecular confirmation of selected protozoans. Soil samples collected from the neighbourhood were analyzed for soil inhabiting parasitic stages. Of the $50 \mathrm{dogs}$ examined, $86.0 \%$ was infected with one or more parasites with a significantly higher number of dogs having mixed infections than single infections. Dogs harboured 13 GI parasites, of which nine were known zoonotic species: Toxocara canis, Strongyloides sp., Entamoeba coli, hookworm, Trichuris sp., Giardia duodenalis, Spirocerca lupi, Toxascaris sp., and Taenia sp. Additionally Entamoeba histolytica, coccidia, unidentified trematodes and cestodes were also found in dogs. Six types of GI parasites were identified in humans, of these four types, E. coli, G. duodenalis, Strongyloides sp. and Blastocystis sp. were potentially acquired from animals. A total of 16 soil samples were analyzed, of which $44.4 \%$ were carrying infective nematode $\mathrm{L}_{3}$ larvae and eggs, cysts of $E$. coli and eggs of T. canis all of which were zoonotic. High prevalence of zoonotic infections in dog population and in soil poses a serious health threat to the community. Results highlight the importance of regular deworming of both humans and dogs and reducing environmental contamination, a One Health approach incorporating veterinary and public health interventions in the surveillance and management of zoonoses.
\end{abstract}

Keywords: zoonoses, gastrointestinal parasites, dogs, humans.

\section{INTRODUCTION}

Gastrointestinal (GI) parasites of companion animals, dogs in particular, can cause serious illness in human as they facilitate zoonotic transmission by acting as a source of infection for people and as a bridge between wildlife and humans. In developing countries, abundance of stray dogs and canine faeces deposited on public and private properties are a recurrent irritant and an important public health issue due to the GI parasites with zoonotic potential (Rai et al.,
2000; Sarvi et al., 2014). Many canine GI parasites exclude their eggs, larvae or oocysts with the dog faeces (Rinaldi et al., 2009). These parasites thrive in conditions with warm temperatures and high humidity especially in communities with low socio-economical standards with overcrowded housing, low sanitation and free roaming dogs with close human-dog interaction. Surveillance of dogs can play a critical role in preventing human illness serving as sentinels for infection.

Zoonotic possibility of dog-inhabiting parasites as Ascaris sp., Trichuris, Toxocara canis, Cryptosporidium, Giardia intestinalis and hymenolepids has been studied in Asia, Australia (Provic and Croese, 1996; Traub et al., 2002; Chattha et al., 2009; Khante et al., 2009; Shalaby et al., 2010; ${ }^{\text {a }}$ gui et al., 2014), Ethiopia (Degefu et al., 2011) and in Italy (Rinaldi et al., 2009). Residents of estate communities might experience higher exposure to some zoonotic parasites than the population in general. A study done by Traub et al., (2005) in a tea growing community in India disclosed the high possibility of dogs to transmit Ascaris sp., Trichuris sp., Giardia duodenalis and hookworm to human. Some of the possible zoonotic GI parasites in Sri Lanka include helminths as Ascaris sp., T. canis and Echinococcus granuloses (Dissanaike, 1993; de Silva et al., 1994; Iddawela et al., 2003) and protozoans like G. duodenalis, Cryptosporidium, Entamoeba sp. (de Silva et al., 1994) and coccidians (Wijesundara, 1995). A study carried out by Sorensen et al. (1994) in a plantation community in Sri Lanka reported a high Ascaris infection in women and children highlighting the fact that a higher risk in places with less sanitary facilities and with congested living conditions. Furthermore, they suggest that, by increasing sanitary facilities, the risk of soil transmitting helminths to the human population can be reduced (Sorensen et al., 1994). Another study reported high prevalence $(50.0 \%)$ of Ascaris sp. in a low country tea plantation in Sri Lanka (Gunawardena et al., 2004) and they point out the risk of Ascaris infection increases with congested living conditions and poor sanitary facilities due to the high level of faecal contamination of such environments. Moreover, these authors highlight that good 
personal hygienic conditions and the boiling of drinking water reduce the risks of Ascaris infection even if the environment is highly contaminated (Gunawardena et al., 2004). A study carried out in a tea plantation in Kandy district reveals the presence of 13 canine GI parasites 11 of which have a zoonotic potential (Perera et al., 2013). Later, in the same tea plantation, high prevalence of Ascaris lumbricoides and a low prevalence of Enterobius vermicularis in the human population was reported with a higher worm burden in children (Galgamuwa et al., 2014). These studies have examined the GI parasites in dogs and humans separately. Here we take a holistic approach to address the connection between health of humans, dogs and the environment of a low income estate community at Lunugala Tea estate in relation to the GI parasites.

\section{MATERIALS AND METHODS}

\section{Study site}

Lunugala tea estate is located in an elevation of about $1,046 \mathrm{~m}$ with temperature between $5.5-35^{\circ} \mathrm{C}$ and an average annual precipitation is between $3000 \mathrm{~mm}-5000 \mathrm{~mm}$. The population is 663 comprising mainly of estate community with a low socio-economic status. Almost all the workers are tea pluckers and rarely employed elsewhere. They live mostly in line houses or small blocks of houses connected together. Both dog and the human population have low sanitation, improper and haphazard waste disposal and overcrowded housing. Large number of stray and owned dogs is found in the locality. According to the Teldeniya Divisional Secretariat reports in 2010, the dog to human ratio was one to five.

\section{Study group}

Faecal samples were collected from 50 dogs (representing one third of the dog population) and 50 human (representing $7 \%$ of the human population) in the selected study area using a convenient sampling technique. Information about the human participants and dogs were collected using a questionnaire. Dogs were either owned or stray. Owned dogs were vaccinated against rabies and may be de-wormed at least once in lifetime. The stray dogs are the street dogs that are not owned, not vaccinated against rabies, not been dewormed and usually fed on garbage. Mostly, the conditions of the owned dogs remain the same beside the vaccination against rabies and mingled with the stray dogs in the neighborhood. Human participants were initially informed about the research and faecal samples were collected from volunteered participants after verbal consent.

\section{Sample Collection}

Fresh faecal samples were collected from 50 dogs and 50 villagers in Lunugala estate in the month of May during a rainy period. Dog samples were collected following the dog until they defecate. Human participants were instructed to place a faecal sample into a vial soon after the defecation. Information about the dog and the human participant such as sex, age, deworming practices was recorded after collecting samples. Later, soil samples were collected from the localities where the parasitic infections were high in order to find out the soil inhabiting stages of parasites. All the samples were brought to the laboratory in a cooler within two hours of collection and were kept at $4{ }^{\circ} \mathrm{C}$ until process.

\section{Faecal analysis}

Faecal samples were analyzed using Sheather's sucrose floatation method and direct iodine smears. Morphological identification was done according to the photo guide and text book "Clinical Parasitology of Dogs" by Dunsmore and Shaw (1990). Length and the width of eggs and cysts were measured under high power $(10 \times 40)$ for morphometric identification of eggs, cysts and larvae using a calibrated eyepiece. For Giardia duodenalis Trichrome staining and molecular methods were used for confirmation.

\section{Sheather's sucrose floatation (Blagburn and Butler, 2006)}

Approximately, $3 \mathrm{~g}$ of the faecal sample was weighed using an electrical balance and taken into a $50 \mathrm{ml}$ centrifuge tube filled with $45 \mathrm{ml}$ of distilled water. Faeces was stirred well using an applicator stick. Then the suspension was centrifuged at $3000 \mathrm{rpm}$ for $20 \mathrm{~min}$ after capping the centrifuge tubes tightly. The supernatant was discarded using a Pasteur pipet. Again the pellet was washed with distilled water followed by two centrifugations to obtain a clear solution. After removing the supernatant, the Sheather's sucrose solution (specific gravity 1.27) was added up to the $45 \mathrm{ml}$ level and then followed by a centrifugation at 3000 rpm for $20 \mathrm{~min}$. Approximately, $5 \mathrm{ml}$ of the top meniscus was aspirated into a $15 \mathrm{ml}$ centrifuge tube. The total volume was made to $14 \mathrm{ml}$ level by adding distilled water and the tube was centrifuged at $3000 \mathrm{rpm}$ for $10 \mathrm{~min}$ at $16{ }^{\circ} \mathrm{C}$. The supernatant was pipetted out leaving approximately $1 \mathrm{ml}$ of supernatant in the tube. The sediment was thoroughly mixed with remaining supernatant and then transferred to a $1.5 \mathrm{ml}$ Eppendorf ${ }^{\circledR}$ microfuge tube using a Pasteur pipette. Distilled water was added up to the $1.5 \mathrm{ml}$ level and was centrifuged for $10 \mathrm{~min}$ at $3500 \mathrm{rpm}$. The supernatant was decant leaving only $0.5 \mathrm{ml}$ in the Eppendorf ${ }^{\circledR}$ microfuge tube and then the pellet was thoroughly mixed and the whole volume in the tube was used to make a microscope slide. Eggs and cysts were identified using the $\times 10$ and $\times 40$ objective lenses, length and width were measured and photographed for further identification.

\section{Iodine smear (Garcia and Bruckner, 1988)}

A drop of Lugols' iodine was laced on a microscopic slide. A small amount of the faecal sample was picked up using a wooden applicator stick and mixed well. For each sample, three smears were prepared and observed under the light microscope using $\times 10$ and $\times 40$ objective lenses. Parasitic eggs and cysts were measured and photographed under $\times 40$ objective for further identification.

\section{Trichrome staining (ThermoFisher ${ }^{\circledR}$ catalog, n.d)}

Trichrome staining was performed for positive samples for Giardia sp. isolated delete resulted from coprological methods. A thin faecal smear was prepared and half dried. 
The smear was fixed using freshly prepared $\mathrm{HgCl}_{2}$ fixative. Then the smear was fixed using $70 \%$ ethanol, $70 \%$ ethanol in Lugols' iodine, $70 \%$ ethanol for $2 \mathrm{~min}, 5 \mathrm{~min}$ and $2 \mathrm{~min}$, respectively. Smear was stained using the Trichrome stain. Excess stain was removed using acid alcohol. The smear was rinsed 2-3 times using 95\% ethanol and fixed using absolute ethanol for $3 \mathrm{~min}$. A drop of depex was placed on the prepared smear and a cover slip was placed. Smear was dried for couple of minutes and observed under light microscope using high power $(\times 40$ objective lens $)$ for protozoans.

\section{Molecular identification}

Samples positive for Giardia sp. by coprological methods were processed for molecular confirmation. Genomic DNA of the parasite was extracted using MO BIO soil extraction kit and amplified by nested Polymerase Chain Reaction (PCR) using specific primers for SSU rRNA gene. For outer PCR Giar RH11 and Giar RH 4 primers were used and then for the nested PCR Giar F and Giar R primers were used (Table 1). Appropriate temperature conditions used in the PCR are given in Table 2. The amplified DNA was visualized by agarose gel electrophoresis. An agarose gel $(0.8 \%)$ was ran under 40 volts for 45 min with Ethidium Bromide as the visualizing dye.

\section{Soil analysis}

Sixteen soil samples were collected from localities where a high incident of infections of human and dog population was found. Soil samples were collected, processed and analyzed according to Horiuchi et al., 2013 and further analysed using Sheather's sucrose floatation method after filtering the larger soil particles out. Larvae and eggs were extracted and identified.

\section{Statistical analysis}

Comparisons between protozoan and helminth infections and differences among the risk groups were carried out using a Chi square test and the analyses were performed using MINITAB Version 17.

\section{Ethical clearance}

Table 1: Primer sequences and melting temperatures used to isolate and amplify DNA of Giardia duodenalis.

\begin{tabular}{llr}
\hline Gene Locus & Sequence from 5'-3' & Melting temperature $\left({ }^{\mathbf{0}} \mathbf{C}\right)$ \\
\hline Giar RH 11 & CATCCGGTCGATCCTGCC & 58.3 \\
Giar RH 4 & GTCGAACCCTGATTCTCCG & 55.7 \\
Giar F & GACGCTCTCCCCAAGGAC & 57.9 \\
Giar R & CTGCGTCACGCTGCTCG & 59.8 \\
\hline
\end{tabular}

Table 2: PCR cycling conditions used during the DNA amplification of Giardia duodenalis.

\begin{tabular}{lll}
\hline & Outer PCR & Nested PCR \\
\hline Initial denaturation & $94{ }^{\circ} \mathrm{C}$ for $5 \mathrm{~min}$ & $94{ }^{\circ} \mathrm{C}$ for $5 \mathrm{~min}$ \\
Denaturation & $94{ }^{\circ} \mathrm{C}$ for $30 \mathrm{~s}$ & $94{ }^{\circ} \mathrm{C}$ for $30 \mathrm{~s}$ \\
Annealing primers & $53{ }^{\circ} \mathrm{C}$ for $1 \mathrm{~min}$ & $56{ }^{\circ} \mathrm{C}$ for $1 \mathrm{~min}$ \\
Extension of strands & $72{ }^{\circ} \mathrm{C}$ for $30 \mathrm{~s}$ & $72{ }^{\circ} \mathrm{C}$ for $30 \mathrm{~s}$ \\
Completion of reaction & $72{ }^{\circ} \mathrm{C}$ for $10 \mathrm{~min}$ & $72{ }^{\circ} \mathrm{C}$ for $7 \mathrm{~min}$ \\
\hline
\end{tabular}
Faculty of Medicine, University of Peradeniya.

\section{RESULTS}

\section{Prevalence of parasites} (Table 3, Figure 1). and Blastocystis sp. (Table 3, Figure 1).

Protocols for faecal sample collection and processing was reviewed and approved by the Ethical Review Committee,

Of the 50 dogs examined, $43(86.0 \%)$ were positive for one or more GI parasites. There was no difference in the prevalence of infection between stray and owned dogs or between male and female dogs (Chi square test, $p>0.05$ ). Adult dogs however, had a significantly higher infection than puppies $\left(\chi^{2}=5.081 ; p=0.024\right)$. Helminth infections were significantly common than protozoan infections $\left(\chi^{2}=\right.$ 21.182; $p<0.001)$. Polyparasitism was significantly higher $(62.8 \%)$ than monoparsitism $\left(\chi^{2}=4.937 ; p=0.026\right)$. None of the dogs had protozoan-protozoan mixed infections. Mixed infections were either helminth-protozoan or helminth-helminth, with no significant difference between the two groups $\left(\chi^{2}=0.486 ; p=0.486\right)$. A total of $13 \mathrm{GI}$ parasite species were found of which, Toxocara canis had the highest prevalence $(28.0 \%)$ followed by Strongyloides sp. (26.0\%), and Entamoeba coli (24.0\%; Table 3). In addition, Trichuris sp., Hookworm, Giardia duodenalis, Spirocerca lupi, Entamoeba histolytica , Toxascaris sp., Taenia sp. and Blastocystis sp. were also recorded in dogs

Of the 50 human samples examined 31 (62.0\%) carried one or more GI parasites. There was no difference in the prevalence of infection between males and females $\left(\chi^{2}=\right.$ 0.764; $p=0.382$ ) or between adults and children (below 12 years of age; $\left.\chi^{2}=2.266 ; p=0.132\right)$. Monoparasitism was significant than polyparasitism $\left(\chi^{2}=10.519 ; p=\right.$ $0.001)$. None of the humans had helminth-heminth mixed infections but protozoan-protozoan mixed infection (37.5\%) and protozoan-helminthes infection (62.5\%) were found. A total of six GI parasites were found in humans with E. coli recording the highest prevalence $(32.0 \%)$ followed by $G$. duodenalis (26.0\%). Other parasites include Ascaris lumbricoides, Strongyloides sp., Balantidium sp.

In the soil samples, $44.4 \%$ were positive for life stages of GI parasites such as infective $\mathrm{L}_{3}$ of nematodes $(11.1 \%)$,

Completion of reaction 


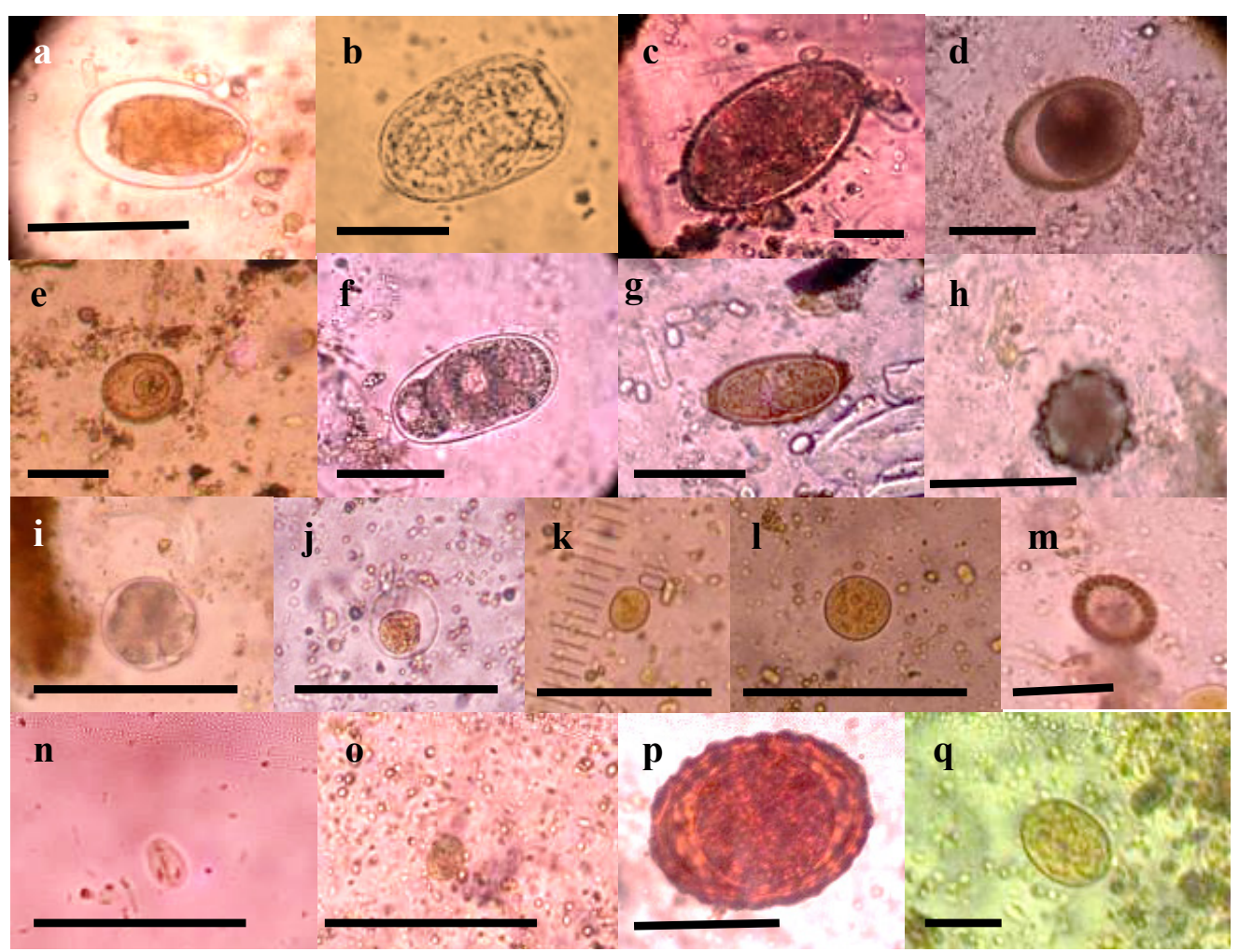

Figure 1: Parasitic stages found in dogs (a, c, d, e, f, g, h, i, k, m and n) and human (b, j, 1, o, p and q). a, b- Strongyloides sp., cunidentified Trematode egg, d- Toxocara canis, e- Toxascaris sp., f- Hookworm, g- Trichuris sp., h- unidentified Cestode egg, i, j - Blastocystis sp., k, 1- Entamoeba coli, m- Taenia sp., n, o- Giardia duodenalis, p- Ascaris sp., and q- Balantidium sp . (Scale bar represent $50 \mu \mathrm{m})$. All images are taken under iodine wet mount under high power.

Table 3: Diversity and prevalence of gastrointestinal parasites in stray and owned dogs.

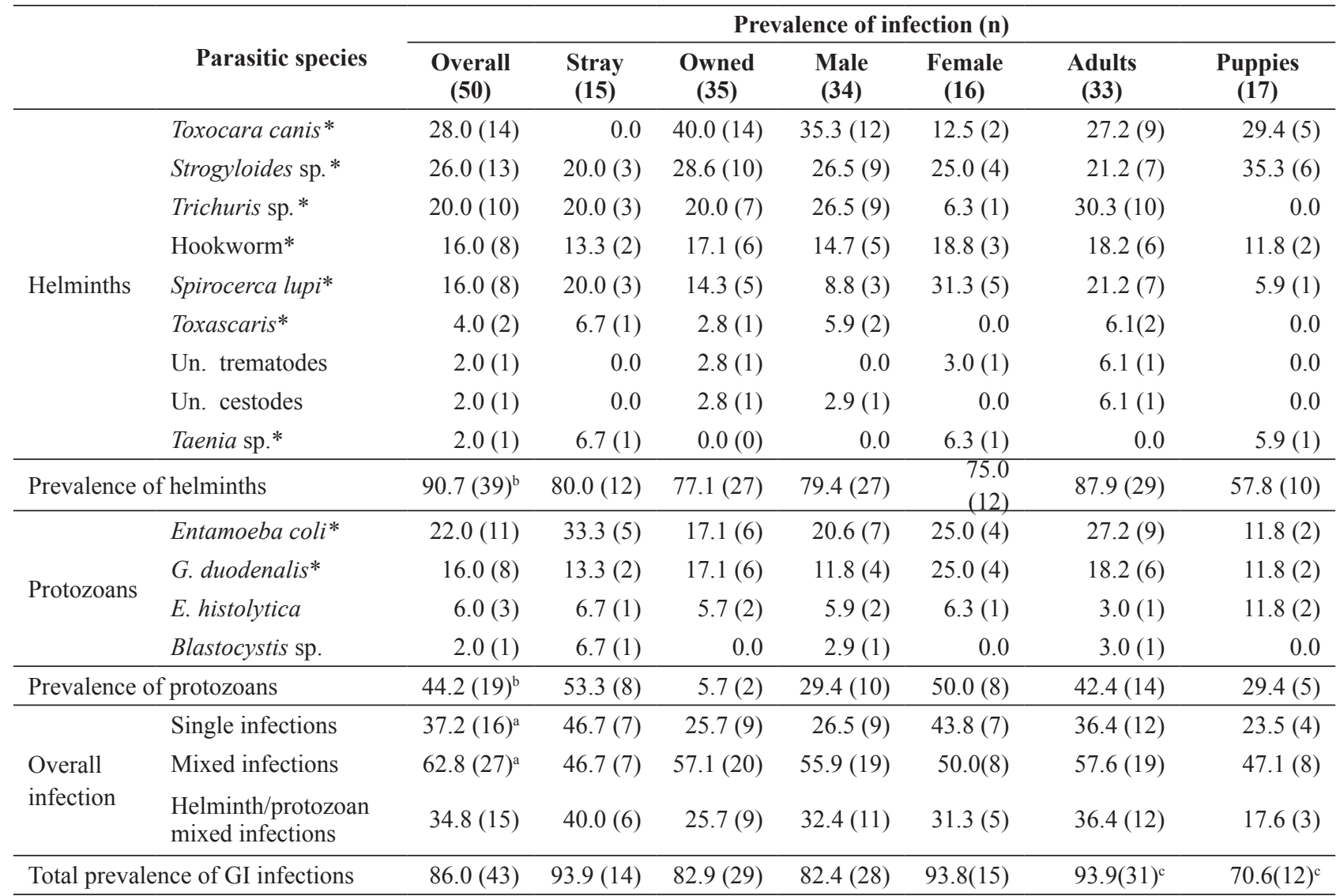

a, b,c denote $\mathrm{p}<005$ Chi square test; Un. $=$ Unidentified; $\mathrm{n}=$ number of samples * potential zoonoses 


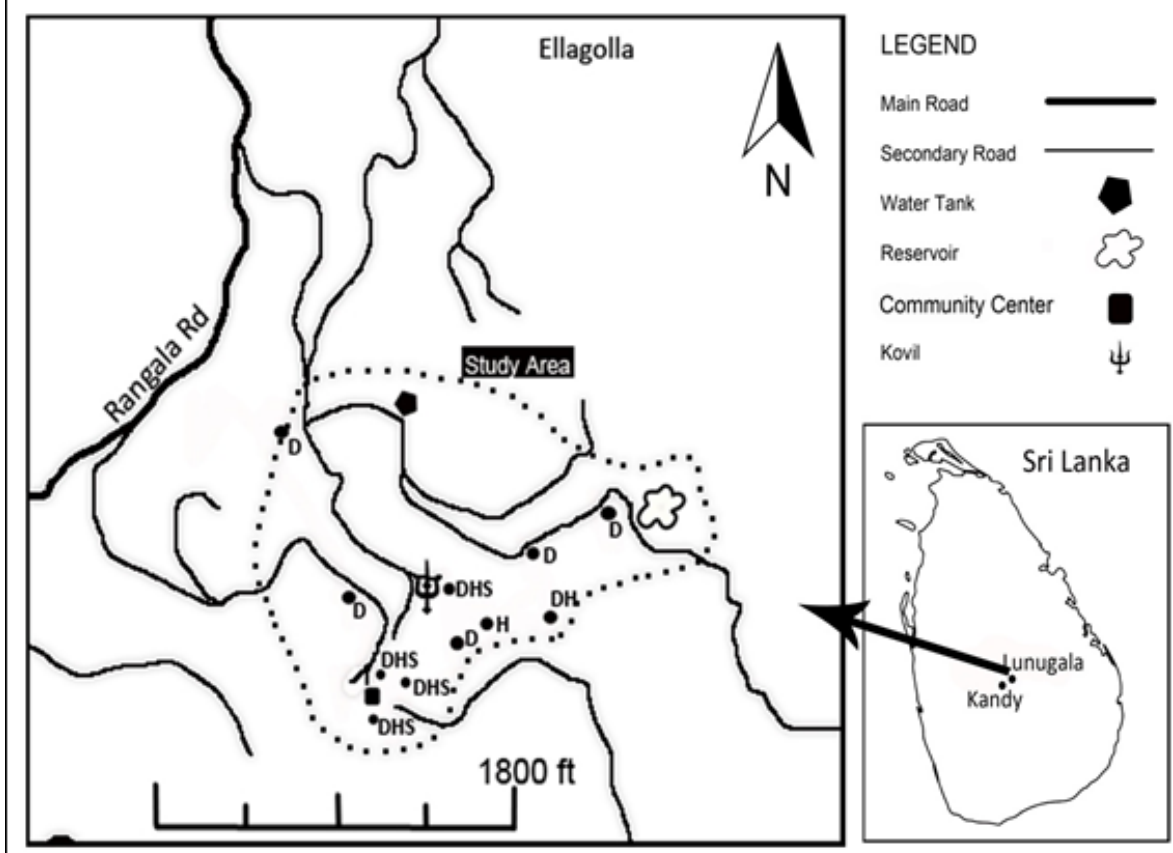

Figure 2: Map showing the study area, "S" represents the localities where the positive soil samples were collected, "H" represents the localities where human faecal samples were positive with parasitic stages and "D" represents the localities where dog faecal samples were positive with parasitic stages.

Table 4: Prevalence of gastrointestinal parasites in human samples.

\begin{tabular}{|c|c|c|c|c|c|c|}
\hline & \multirow{2}{*}{ Parasitic species } & \multicolumn{5}{|c|}{ Prevalence of infection (n) } \\
\hline & & Overall & Male (25) & Female (25) & Adults (14) & Children (36) \\
\hline \multirow{2}{*}{ Helminths } & A. lumbricoides & $18.0(9)$ & $12.0(3)$ & $24.0(6)$ & $28.6(4)$ & $11.1(4)$ \\
\hline & Strongyloides* & $2.0(1)$ & 0.0 & $4.0(1)$ & 0.0 & $2.8(1)$ \\
\hline \multicolumn{2}{|c|}{ Helminth infections } & $35.5(11)$ & $12.0(3)$ & $32.0(8)$ & $35.7(5)$ & $16.7(6)$ \\
\hline \multirow{4}{*}{ Protozoans } & E. coli* & $32.0(16)$ & $24.0(6)$ & $40.0(10)$ & $57.1(8)$ & $22.2(8)$ \\
\hline & G. duodenalis* & $26.0(13)$ & $28.0(7)$ & $24.0(6)$ & $35.7(5)$ & $22.2(8)$ \\
\hline & Balantidium sp. & $2.0(1)$ & $4.0(1)$ & 0.0 & 0.0 & $2.8(1)$ \\
\hline & Blastocystis sp. ${ }^{*}$ & $2.0(1)$ & 0.0 & $4.0(1)$ & 0.0 & $2.8(1)$ \\
\hline \multicolumn{2}{|c|}{ Protozoan infections } & $80.6(25)$ & $48.0(12)$ & $52.0(13)$ & $64.3(9)$ & $44.4(16)$ \\
\hline \multirow{3}{*}{$\begin{array}{l}\text { Overall } \\
\text { infection }\end{array}$} & Single infections & $74.2(23)^{\mathrm{a}}$ & $48.0(12)$ & $44.0(11)$ & $42.8(6)$ & $47.2(17)$ \\
\hline & Mixed infections & $25.8(8)^{\mathrm{a}}$ & $8.0(2)$ & $24.0(6)$ & $35.7(5)$ & $8.3(3)$ \\
\hline & $\begin{array}{l}\text { Helminth/protozoan } \\
\text { mixed infections }\end{array}$ & $16.1(5)$ & $4.0(1)$ & $16.0(4)$ & $21.4(3)$ & $5.6(1)$ \\
\hline \multicolumn{2}{|l|}{ Overall } & $62.0(31)$ & $56.0(14)$ & $68.0(17)$ & $78.6(11)$ & $55.6(20)$ \\
\hline
\end{tabular}

${ }^{\mathrm{a}}$ denotes $\mathrm{p}<005$ Chi square test; $\mathrm{n}=$ number of samples $*$ potential zoonoses

cysts of E. coli $(22.2 \%)$ and eggs of T. canis (11.1\%), all of which were zoonotic. Soil samples were collected (denote "S" in Figure 2) from the localities where the human and dog had positive samples (denote "H" and "D" in Figure 2).

\section{Zoonotic potential}

Of the 13 GI parasites in dogs, nine were zoonotic: $T$. canis, Strongyloides sp., hookworm, E. coli, Trichuris sp., G. duodenalis, Spirocerca lupi, Toxascaris sp. and Taenia sp. and of the six GI parasites in humans four: (E. coli, G. duodenalis, Strongyloides sp. and Blastocystis) were potentially zoonotic (Table 3 and 4).

\section{DISCUSSION}

Results show that the majority of the dogs in the Lunugala tea estate were infected with one or more GI parasites. Veterinary care facilities of state sector were extremely limited and people do not seek any accessible private facilities due to their low economic level, thus none of these dogs had been treated for worm infections. Infections of GI parasites in dogs are higher in developing countries and especially in communities with low socio-economic conditions like tea estate communities where living standards are not up to the accepted levels (Sherman, 2010; IFAD, 2014). A study carried out in Hantana tea estate area in Kandy district, in the Central Sri Lanka reported $90.0 \%$ of the dogs are infected with GI parasites (Perera et al., 2013) and a tea estate community in India recorded $99.0 \%$ of the dogs examined are infected with GI parasites (Traub, 2013). There was no difference in the prevalence 
of GI infections between stray and owned dogs. All the dogs faced similar hygienic and health conditions, whether owned or stray, lived outdoors and were permitted to mingle and roam freely. Lack of deworming, and scavenging on improperly disposed garbage are likely routes of parasitic infection. There was no difference in the prevalence of GI parasites between male and females dogs, but the adults carried significantly more infections than puppies, this is however, on the contrary to the general consensus that the prevalence of GI parasites is higher in puppies than in adults as puppies are at higher risk of trans-placental and trans-mammary transmission (Schantz, 1999) and lack of acquired immunity after repeated exposures (RamirezBarrios et al., 2004). However, Fontanarrosa et al. (2006) argue that higher infection rates in older dogs could be caused by parasites that are not transmitted to dogs at early age or by parasites that do not elicit an immune response.

In regards to species composition, a total of $13 \mathrm{GI}$ parasites were found in dogs and of these, nine were zoonotic: Toxocara canis, Strongyloides sp., E. coli, Trichuris sp., hookworm, G. duodenalis, S. lupi, Toxascaris sp., and Taenia sp. In Sri Lanka, early records indicate zoonoses of Toxoplasma gondii, Echinococcus granuloses, Ancylostoma caninum, A. braziliense, Diphylobothrium latum and T. canis (Dissanaike, 1961; Senadhira, 1967; Dissanaike, 1995) and more recently Isospora sp, Cyclospora sp and Capillaria aerophyla, (Perera et al., 2013) were recorded in dogs. Moreover, adult tapeworm of Echinococcus granuloses has been recorded in a dog in Kandy district (Dissanaike 1957; 1961). Although the present study reports the hookworm infections in dogs, the species had not been identified. In a study more than five decades ago Dissanaike $(1957 ; 1961)$ reported the existence different hookworm species like A. caninum, $A$. ceylanicum and $A$. lumbricoides in dogs and other studies report they can also be found to a lesser extend in humans as well (Rinaldi et al., 2009; Bowman et al., 2010; Shalaby et al., 2010; Inpankaew et al., 2012; Traub, 2013; Ngui et al., $2014 \mathrm{a}, \mathrm{b})$.

In the tea estate community, $72.0 \%$ was infected with one or more GI parasites and of which $28.0 \%$ had mixed infections and protozoan infections were more common than helminths. This could be due to administration of anthelminthic drugs especially to children, although not regular and proper. The estate management together with the Ministry of Health conducts mobile clinics for vaccinations and deworming once in every six months. However, proper administration of the recommended dosage is questionable as the education level of the community is low (Personal communication with Estate Management). Protozoans are important etiological agents of waterborne diarrheal diseases (Shortt et al., 2006) and Southeast Asian countries diarrheal diseases is a major reason of morbidity and mortality, especially among children (Perera et al., 1999; Traub et al., 2005; WHO, 2005). In Sri Lanka, there are records of increased contamination of drinking water with protozoan cysts like G. duodenalis and Cryptosporidium sp. (Shortt et al., 2006). Studies around the world have shown variable occurrences of human infection by Toxocara sp. (Itoh et al., 2009; Sharif et al., 2010). For instance, in
USA alone 10,000 cases are recorded annually (Sarvi et al., 2014). In Sri Lanka, 43\% seroprevalence for Toxocara canis has been recorded by Iddawela et al., (2003) with a higher prevalence in children.

Soil samples had different life stages of GI parasites such as infective $\mathrm{L}_{3}$ of nematodes, cysts of $E$. coli and eggs of T. canis. In Lunugala estate, $11.1 \%$ of the soil samples were infected with $T$. canis eggs. Presence of $T$. canis eggs in the soil in public parks in Great Britain have been reported (Chiodo et al., 2006; Talaizadeh et al., 2007). In addition, many other studies report the presence of to $T$. canis in soil, together with other infections such as $A$. lumbricoides, T. vulpis, Ancylostoma sp., Giardia sp. and Cryptosporidium sp. in soil (Rubel and Wisnivesky, 2005; Itoh et al., 2009; Stojcevic et al., 2010).

A very important, widely present zoonotic parasite, Cryptosporidium was not encountered in any of the samples. This could be because the coprological examinations done were not specifically designed to extract or identify Cryptosporidium, and therefore the Cryptosporidium cases might be seriously undermined during the study. Studies done on human and dog faecal and drinking water of Sri Lanka indicates high prevalence of this zoonotic protozoan (de Silva et al., 1994; Iddawela et al., 2003; Shortt et al., 2006; Perera et al., 2013).

This study involving animal, human and environment with a One Health approach offers information on the potentially zoonotic parasites in dog faeces and environment of the Lunugala tea estate community. Dogs provide a constant reservoir of parasites to the human community. Since the houses were clustered and crowded, animals were kept in close proximity to human who defecate in the compound makes household members posing a high risk to the community. Traub et al., (2013) in a similar community discloses the need in health education and risk management practices in order to lessen the infection ratio among dogs and human.

\section{ACKNOWLEDGEMENT}

Technical assistance was given by Mr. K. B. A. T. Bandara, Staff Technical Officer, Department of Veterinary Pathobiology, Faculty of Veterinary Medicine and Animal Sciences, University of Peradeniya, Peradeniya, Sri Lanka.

\section{REFERENCES}

Blagburn B.L. and Butler J.M. (2006). Optimize intestinal parasite detection with centrifugal faecal flotation. Veterinary Medicine. 101: 455-464.

Bowman D.D., Montgomery S.P., Zajac A.M., Eberhard M.L. and Kazacos K.R. (2010). Hookworms of dogs and cats as agents of cutaneous larva migrans. Trends in Parasitology. 26:162-167. DOI: 10.1016/j. pt.2010.01.005. Epub 2010 Feb 25.

Chattha M.A., Aslam A., Rehman Z.U., Khan J.A. and Avias M. (2009). Prevalence of Toxocara canis in dogs and its effects on various blood parameters in Lahore (Pakistan). Journal of Animal and Plant Sciences. 19: 71-73: DOI: 19-2- 2009/09-922R.pdf.

Chiodo P., Basualdo J., Cirmela L., Pezzani B., Apezteguia 
M. and Minvielle M. (2006). Related factors of human toxocariasis in a rural community of Argentina. Memórias do Instituto Oswaldo Cruz. 101: 397-400.

de Silva N.R., de Silva H.J. and Jayapani V.P. (1994). Intestinal parasitoses in the Kandy area, Sri Lanka. Southeast Asian Journal of Tropical Medicine and Public Health. 25:469-73.

Degefu H., Tefera A. and Yohannes M. (2011) Zoonotic helminth parasites in faecal samples of household dogs in Jimma Town, Ethiopia. Journal of Public Health and Epidemiology. 3:138-143: DOI: article1379425925_ Degefu et al.pdf . Accessed on Sep 2016.

Dissanaike A.S. (1957). Some preliminary observations on Echinicoccus infection in local cattle and dogs. Ceylon Medical Journal. 4:69-75.

Dissanaike A.S. (1961). On some helminths of dogs in Colombo and their bearing on human infections, with a description of a new trematode Heterophyopsis yehi Nov. (Heterophyidae). Ceylon Medical Journal 10:112.

Dissanaike A.S. (1993). Parasitic zoonoses in Sri Lanka. Ceylon Medical Journal 38: 150-4 and 184-7.

Dissanaike A.S. (1995). Uncommonly reported parasitic infections of childhood and parasites of the future. Ceylon Journal of Child Health 24: 1-8.

Dunsmore J.D. and Shaw S.E. (1990). Clinical Parasitology of Dogs, Post Graduate Foundation in Veterinary Science, The University of Sydney, Australia. Pp. 1 145.

Fontanarrosa, M.F., O’vezzani, D., Basabe, J., and Diego, F.E. (2006) An epidemiological study of gastrointestinal parasites of dogs from Southern Greater Buenos Aires (Argentina): Age, gender, breed, mixed infections, and seasonal and spatial patterns. Veterinary Parasitology 136:283-295.

Galgamuwa G.L.S. and Iddawela W.M.D.R. (2014). Prevalence and factors associated with intestinal nematode infections among children in the Hantana tea estate, Kandy. Proceedings of the Peradeniya University International Research Sessions, University of Peradeniya, Sri Lanka, pp.348.

Garcia L.S. and Bruckner D.A. (1988). Diagnostic Medical Parasitology. New York: Elsevier.

Gunawardena G.S.A., Karunaweera N.D. and Ismail M.M. (2004). Socio-economic and behavioral factors affecting the prevalence of Ascaris infection in a lowcountry tea plantation in Sri Lanka. Annals of Tropical Medicine Parasitology. 98: 615-621(7).

Horiuchi, S., Paller, V.G.V. and Uga, S. (2013). Soil contamination by parasite eggs in rural village in the Philippines. Tropical Biomedicine. 30: 495-503

Iddawela D.R., Kumarasiri P.V. and de Wijesundera M.S. (2003). A seroepidemiological study of toxocariasis and risk factors for infection in children in Sri Lanka. Southeast Asian Journal of Tropical Medicine and Public Health. 34(1): 7-1.

International Fund for Agricultural Development (2004). Livestock Services and the Poor. Rome. Available online at: http://www.ifad.org/lrkm/book/english.pdf. Accessed on September 28, 2014.

Inpankaew T., Schär F., Dalsgaard A., Khieu V., Chimnoi
W., Chhoun C., Sok D., Marti H., Muth S., Odermatt P. andTraub R.J. (2012). High prevalence of Ancylostoma ceylanicum hookworm infections in humans, Cambodia. Emerging Infectious Diseases. DOI: 10.3201/eid2006.131770.

Itoh N., Kanai K., Hori Y., Hoshi F. and Hiquchi S. (2009). Prevalence of Giardia intestinalis and other zoonotic intestinal parasites in private household dogs of the Hachinohe area in Aomori prefecture, Japan in 1997, 2002 and 2007. Journal of Veterinary Sciences. 10:305308.

Khante G.S., Khan L.A., Bodkhe A.M., Suryawanshi P.R. Majed M.A. Suradkar U.S. and Gaikwad. S.S. (2009). Epidemiological survey of Gastro-intestinal Parasites of Non-descript dogs in Nagpur City. Veterinary World. 2:22-23.

Ngui R., Lee S.C., Yap N.J., Tan T.K., Aidil R.M., Chua K.H., Aziz S., Sulaiman W.Y., Ahmad A.F., Mahmud R. and Lian Y.L. (2014a). Gastrointestinal parasites in rural dogs and cats in Selangor and Pahang states in Peninsular Malaysia. Acta Parasitologica. 59:737-44. DOI: 10.2478/s11686-014-0306-3.

Ngui R., Lim Y.A.L., Ismail W.H.W., Lim K.N. and Mahmud R. (2014b). Zoonotic Ancylostoma ceylanicum Infection Detected by Endoscopy. American Journal of Tropical Medicine and Hygiene. 291: 86-88: DOI:10.4269/ajtmh.13-0756.

Perera J., Jayawardene I., Mendis L. and Abeyratne K. (1999). Intestinal parasites and diarrhoea in a children's hospital in Sri Lanka. Ceylon Medical Journal. 42: 7-12.

Perera P.K., Rajapakse R.P.V.J. and Rajakaruna R.S. (2013). Gastrointestinal parasites of dogs in Hantana area in Kandy district. Journal of National Science Foundation of Sri Lanka. 41: 83-93. http://dx.doi. org/10.4038/jnsfsr.v41i2.5703.

Prociv P. and Croese J. (1996). Human enteric infection with Ancylostoma caninum: hookworms reappraised in the light of a "new" zoonosis. Acta Tropica. 62: 23-44: DOI: 10.1016/S0001-706X(96)00016-2.

Rai S.K., Uga S., Ono K., Rai G. and Matsumara T. (2000). Contamination of soil with helminth parasite eggs in Nepal. Southeast Asian Journal of Tropical Medicine and Public Health. 31: 388-393. DOI: 10.1371/journal. pntd.0002634.

Rami'rez-Barrios, R.A., Barboza-Mena, G., Muñoz, J., Angulo-Cubilla'n, F., Herna'ndez, E., Gonza'lez, F., Escalona, F. (2004). Prevalence of intestinal parasites in dogs under veterinary care in Maracaibo, Venezuela. Veterinary Parasitology. 121: 11-20.

Rinaldi L., Biggeri A., Carbone S., Musella V., Catelan D., Veneziano V. and Cringoli G. (2009). Canine faecal contamination and parasitic risk in the city of Naples (southern Italy). BMC Veterinary Research. 2: 29 p.

Rubel D. and Wisnivesky C. (2005). Magnitude and distribution of canine faecal contamination and helminth eggs in two areas of different urban structure, Greater Buenos Aires, Argentina. Veterinary Parasitology. 133: 339-347: DOI: pubmed/16023293.

Sarvi S., Daryani A., Sharif M., Rahimi M.T., Azami D., Marhaba Z., Ahmadpour E. and Mizani A. (2014). 
Domestic dog as a human health hazard in north of Iran. Journal of Parasitic Diseases. DOI 10.1007/s12639014-0608-2.

Schantz, P.M., (1999). Intestinal parasites of dogs in Western Australia: progress in control and new concerns. Veterinary Journal. 157: 222-224.

Senadhira, M.A.P. (1967). The parasites of Ceylon ii, Trematoda. Sri Lanka Veterinary Journal. 15: 33-41.

Shalaby H.A., Abdel-Shafy S. and Derbala A.A. (2010). The role of dogs in transmission of Ascaris lumbricoides for humans. Parasitology Research. 106: 1021-6. DOI: 10.1007/s00436-010-1755-8.

Sharif M., Daryani A., Barzegar G., Nasrolahei M. and Khalilian A. (2010). Seroprevalence of toxocariasis in schoolchildren in Northern Iran. Pakistan Journal of Biological Sciences. 13:180-184.

Sherman D.M. (2010). A Global Veterinary Medical Perspective on the Concept of One Health: Focus on Livestock. ILAR Journal. 51(3): 281-287: DOI: 10.1093/ilar.51.3.281

Shortt R.L., Boelee E., Matsuno Y., Madramootoo C., van der Hoek W. and Faubert G. (2006). Cryptosporidium and Giardia as determinants for selection of an appropriate source of drinking-water in Southern Sri Lanka. Journal of Health, Population and Nutrition. 24(1): 64-70.

Sorensen E., Ismail M., Amarasinghe D.K., Hettiarachchi I. and Dassenaieke T.S. (1994). The effect of the availability of latrines on soil-transmitted nematode infections in the plantation sector in Sri Lanka. American Journal of Tropical Medicine and Hygiene. 51(1): 6-9: DOI: pubmed/8059913.

Stojčević D., Sušić V. and Lučinger S. (2010). Contamination of soil and sand with parasite elements as a risk factor for human health in public parks and playgrounds in Pula, Croatia. Veterinary Archives. 80(6): 733-742.

Talaizadeh A., Maraghi S., Jelowdar A. and Peyvasteh M. (2007). Human toxocariasis: a report of 3 cases. Pakistan Journal of Medical Sciences. 23: 782 - 784.

Teldeniya Divisional Secretariat Report, (2010). Teldeniya Divisional Secretariat. [Accessed on 2017/05].

Thermo Fisher Scientific ${ }^{\circledR}$. (n.d.). Parasitology Systems; Application for Trichrome Stain. ProtocolTM. Middletown, VA, 22645-1905 USA.

Traub R.J., Robertson I.D., Irwin P., Mencke N. and Thompson R.C. (2002). The role of dogs in transmission of gastrointestinal parasites in a remote tea-growing community in Northeastern India. American Journal of Tropical Medicine and Hygiene. 67(5): 539-545: DOI: pubmed/12479559.

Traub R.J., Robertsona I.D., Irwina P.J., Mencke N. and Thompson R.C. (2005). Canine gastrointestinal parasitic zoonoses in India. Trends in Parasitology. 21: 42-48.

Traub R.J. (2013). Ancylostoma ceylanicum, a re-emerging but neglected parasitic zoonosis. International Journal of Parasitology. 43:1009-15: DOI: 10.1016/j. ijpara.2013.07.006.

World Health Organization (2006). The Control of Neglected Zoonotic Diseases: A Route to Poverty Alleviation. Available online at: http://whqlibdoc. who.int/publications/2006/9789241594301_ eng.pdf Accessed September 28, 2015.

Wijesundera M.S. (1995). Challenges in Parasitology: A Sri Lankan perspective. Ceylon Medical Journal 38:2529.

\section{APPENDIX}

Appendix 1: Morphometric analysis of parasite eggs and cysts in dog and human faeces.

\begin{tabular}{|c|c|c|c|c|c|c|}
\hline \multirow[b]{2}{*}{ Parasitic Species } & \multicolumn{3}{|c|}{ Dogs } & \multicolumn{3}{|c|}{ Humans } \\
\hline & $\mathbf{n}$ & $\begin{array}{c}\text { Length } \\
(\text { Mean } \pm \text { SD })\end{array}$ & $\begin{array}{c}\text { Width } \\
(M e a n \pm S D)\end{array}$ & $\mathbf{N}$ & $\begin{array}{c}\text { Length } \\
(\text { Mean } \pm \text { SD })\end{array}$ & $\begin{array}{c}\text { Width } \\
(M e a n \pm \text { SD })\end{array}$ \\
\hline Toxocara canis & 14 & $80.5 \pm 3.0$ & $71.9 \pm 1.7$ & - & - & - \\
\hline Strogyloides sp. & 13 & $52.5 \pm 8.2$ & $36.8 \pm 6.2$ & 1 & $100.3 \pm 2.1$ & $52.3 \pm 2.1$ \\
\hline Trichuris sp. & 10 & $53.7 \pm 2.4$ & $23.9 \pm 2.3$ & - & - & - \\
\hline Hookworm & 8 & $64.1 \pm 2.8$ & $36.4 \pm 2.3$ & - & - & - \\
\hline Spirocerca lupi & 8 & $33.4 \pm 3.0$ & $12.5 \pm 1.9$ & - & - & - \\
\hline Toxascaris & 2 & $74.5 \pm 2.3$ & $64.2 \pm 2.3$ & - & - & - \\
\hline Unidentified Trematodes & 1 & $158.0 \pm 1.4$ & $92.5 \pm 6.4$ & - & - & - \\
\hline Unidentified Cestodes & 1 & $44.3 \pm 3.1$ & $35.3 \pm 0.6$ & - & - & - \\
\hline Taenia sp. & 1 & $36.3 \pm 1.5$ & $30.0 \pm 1.0$ & - & - & - \\
\hline Entamoeba coli & 11 & $12.1 \pm 1.9$ & - & 16 & $11.5 \pm 2.7$ & \\
\hline Giardia duodenalis & 8 & $13.8 \pm 1.0$ & $11.1 \pm 16.4$ & 13 & $14.9 \pm 0.8$ & $8.4 \pm 0.7$ \\
\hline Entamoeba histolytica & 3 & $21.7 \pm 1.4$ & $12.4 \pm 1.1$ & - & - & - \\
\hline Blastocystis sp. & 1 & $10.0 \pm 1.0$ & $7.7 \pm 0.6$ & 1 & 12.0 & 9.0 \\
\hline A. lumbricoides & - & - & - & 9 & $73.1 \pm 1.6$ & $43.9 \pm 2.9$ \\
\hline Balantidium sp. & - & - & - & 1 & $70.5 \pm 2.1$ & $52.0 \pm 1.4$ \\
\hline
\end{tabular}

